\section{Numerical Study of Flow and Heat Transfer Characteristics on Flat Fin with Staggered Tube Arrangement in Transitional Turbulent Flow}

\author{
Mahadika Favian Alfandaviska, Prabowd \\ Department of Mechanical Engineering, Institut Teknologi Sepuluh Nopember, Surabaya 60111, Indonesia \\ Received: 26 February 2020, Revised: 9 September 2020, Accepted: 12 September 2020
}

\begin{abstract}
Three-dimensional computational fluid dynamic simulations were conducted for flow and heat transfer characteristics around flat fin with staggered tube arrangement to fulfill the cooling performance of the tube fin heat exchanger. Fins are generally used to increase the heat transfer area, so the fin material has a high impact on the heat transfer rate. The material wall fin and tube were changed in three steps: aluminum, steel, copper with two different velocities of 8 and $15 \mathrm{~m} / \mathrm{s}$ flowing between fins. The geometry of the flat fin and tube used staggered tube arrangement using transversal spacing, ST, of $11.8 \mathrm{~mm}$, longitudinal spacing, SL, of $22.2 \mathrm{~mm}$, and flow depth $66.6 \mathrm{~mm}$. GAMBIT 2.6 software was used to meshing the geometry, and FLUENT 18.0 was implemented to simulate flow and heat transfer. The results show that the fin with copper material has a more uniform temperature distribution along the fin than the other materials. This indicates that the copper material has a higher heat transfer rate compared to aluminum and steel. Furthermore, increasing velocity will make the separation point formation farther behind the tube and decrease the recirculation zone. Moreover, $8 \mathrm{~m} / \mathrm{s}$ has a lower outlet temperature than $15 \mathrm{~m} / \mathrm{s}$. As a result, $8 \mathrm{~m} / \mathrm{s}$ and copper material have the highest effectiveness of 16.47 and efficiency of $88.35 \%$. The use of copper and aluminum as fin material will also have the relatively same performance in the heat exchanger.
\end{abstract}

Keywords: Flat fin, staggered tube, temperature contour, fin efficiency

\section{Introduction}

The finned tube heat exchanger is applied in a compact heat exchanger to increase the heat transfer area with the smallest weight. The material selection for fin has a significant effect on the performance of the heat exchanger. Chavan et al. [1] performed an experiment and found out that the conduction coefficient has a significant effect on the performance of the heat exchanger due to increasing the heat transfer. The temperature distribution becomes evenly distributed along the fin and make the heat flux from the fin to the air become higher. Furthermore, Kim et al. [2] and D.G. Rich [3, 4] found as the increasing of the number of rows and decreasing of the fin pitch will make the heat transfer coefficient become higher. Wang et al. [5], Jang et al. [6], and Yan et al. [7] found that the increase of tube row number is not necessary for a number of tube row greater than four, and that the staggered configuration is more beneficial.

The effect of variating inlet velocity of the compact heat exchanger also has importance in heat transfer coefficient. Whan et al. [8] establish that the transition flow regime occurs for the Reynold number between 2,700 until 3,300. Moreover, Elsayed et al. [9] and Jamshidi et al. [10] experimental results increasing the inlet velocity of the tube fin heat exchanger, the convection heat transfer

\footnotetext{
*Corresponding author. Email: prabowo@me.its.ac.id
}

coefficient of the flow become higher. However, Awais et al. [11] and Basri et al. [12] noticed that with increasing velocity, the pressure drop becomes higher and makes the fin efficiency become lower. Furthermore, Bolaji et al. [13] found after increasing inlet velocity at a certain point, the effectiveness of the heat exchanger will decrease due to the pressure drop. Pandey et al. [14] also found that the increase of the velocity will make the pumping power also increase and make the efficiency of the heat exchanger become lower.

In addition, there are also several simulations have been carried out regarding the tube fin heat exchanger. Ghori et al. [15] observed that for the laminar flow, the best turbulence model to be used is the laminar model, the SST K-Omega model for the transitional flow, and the realizable K-Epsilon model for the turbulent flow. Nurdiansyah et al. [16] also give some parameters to represent the heat exchanger performance like temperature distribution and efficiency.

All the works mentioned above have not analyzed the correlation between fin materials and velocity inlet in terms of heat transfer coefficient. This study evaluates the effect of the materials fin and heat transfer characteristics around fin and tubes. The present study will be presented contour temperature, velocity, effectiveness and also efficiency of the fin. Furthermore, the temperature 
distribution, efficiency, and effectivity of the fin will be analyzed in different material fin and velocity.

\section{Numerical Method}

2.1. Computational domain and Boundary Condition of Fin Tube

Figure 1 shows the computational domain and geometric parameter of the fin and tube arrangement for the simulation models. The tube arrangement consists of 4 tube rows along longitudinal flow direction with a fin pitch of $1.8 \mathrm{~mm}$. Tube diameter $8 \mathrm{~mm}$ and the tube pitch $\mathrm{S}_{T}=11.8 \mathrm{~mm}$ and $\mathrm{S}_{L}=22.2 \mathrm{~mm}$, respectively.

The computational domain and boundary condition of the simulation have shown in Figure 2 with the following condition:

- Inlet air velocity using the uniform velocity of 8 $\mathrm{m} / \mathrm{s}$ with Reynolds number $2,437.6$ in the transition regime, however $15 \mathrm{~m} / \mathrm{s}$ with Reynolds number 4,570.5 in turbulent regime.

- Inlet air temperature is constant at $301 \mathrm{~K}$.

- The air is considered incompressible with constant properties and no-slip conditions at the surface.

- Outlet boundary as an outflow.

- The symmetry boundary conditions are used at the top and bottom.
- Thermal conductivities for the three kinds of material of fin and tube wall are copper $(\mathrm{k}=385 \mathrm{~W} / \mathrm{m}-\mathrm{K})$, aluminum $(\mathrm{k}=202.4 \mathrm{~W} / \mathrm{m}-\mathrm{K})$, and steel $(\mathrm{k}=16.27$ $\mathrm{W} / \mathrm{m}-\mathrm{K})$, respectively.

- Tube wall using constant temperature at $315 \mathrm{~K}$

The geometry and computational domain were created using the GAMBIT software by using hexahedral element meshes and cooper meshing scheme for the volume meshing, as shown in Figure 3. The total number of the mesh created is 2,600,000 based on the grid independency test. The number of mesh was obtained by verifying the accuracy and the validity of the numerical result using the grid independence test. For this purpose, four mesh systems, 500,000; 1,700,000; 2,600,000; and 3,200,000 are tested. It is observed that for velocity inlet $8 \mathrm{~m} / \mathrm{s}$, the relative errors in temperature and velocity between the result of 2,600,000 and 3,200,000 are less than $2 \%$.

\subsection{Computational Details}

The numerical solution of the Navier-Stokes and energy equation has been done using ANSYS FLUENT 18.1. A control-volume-based technique was used by FLUENT to convert the governing equations to algebraic equations that can be solved numerically. Based on the turbulence model variation of the previous investigation, Ghori et al. [15] showed that the transition flow regime used K-Omega turbulence models, and the turbulent flow regime used K-Epsilon turbulence models.

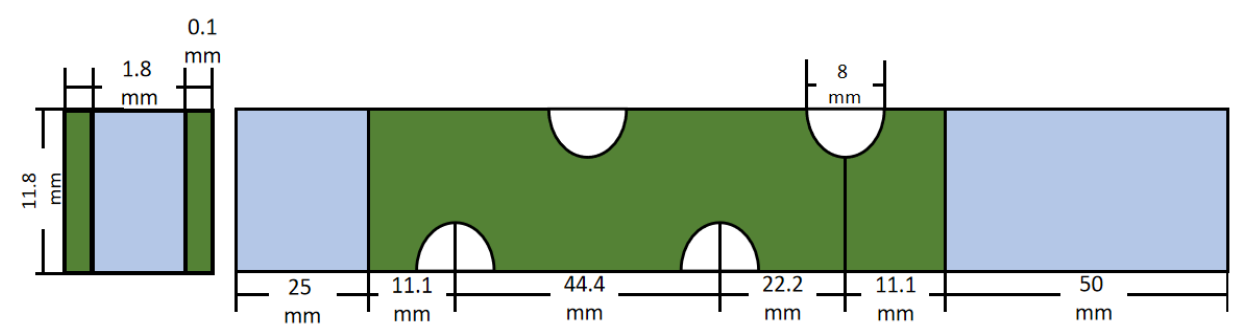

Figure 1. Computational domain and geometric parameter

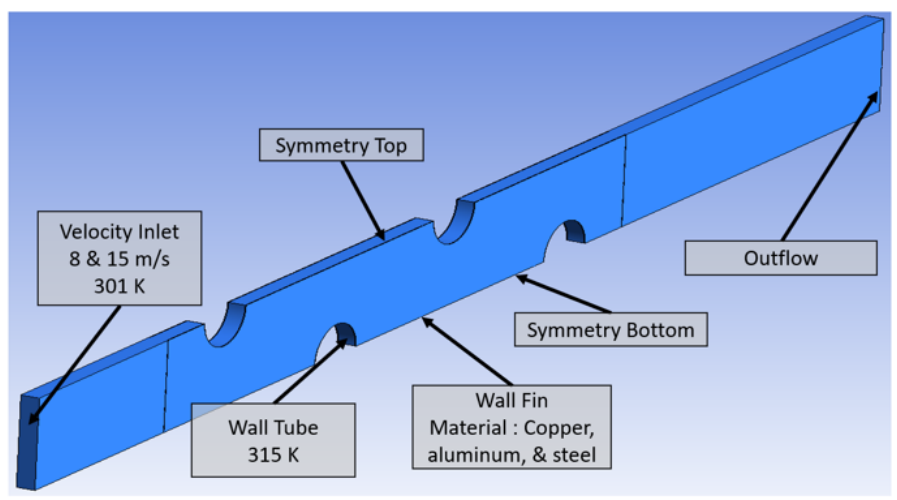

Figure 2. Computational domain and boundary conditions 


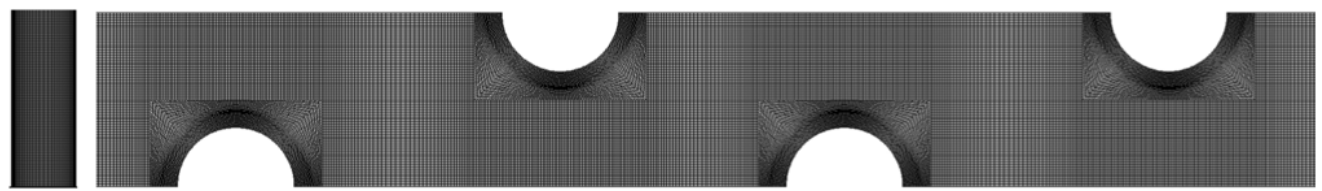

Figure 3. Computation mesh

Steady-state solver of Fluent used for the numerical simulation. The SIMPLE scheme was implemented to analyze the pressure and velocity. The second-order upwind scheme was applied to interpolate the value on the control volume faces. The residuals used for continuity, velocity components, turbulent kinetic energy, and turbulent dissipation rates are under $10^{-6}$ for convergence solution.

\subsection{Analytical efficiency and effectiveness of the Fin}

To analyze the performance of the heat exchanger, the efficiency and the effectiveness of the fin must be calculated. In this study, the analytical method used by Incropera [17] is followed. The effective area of the fin is given by:

$$
A_{f}=2 \times\left(\left(H_{f} \times L_{f}\right)-\left(\frac{\pi \times D_{0}^{2} \times N_{t}}{4}\right)\right) \times N_{f}
$$

Where $H_{f}$ is height of fin, $L_{f}$ is width of fin, $D_{o}$ is outside diameter of tube, $N_{t}$ is number of tube, and $N_{f}$ is number of fin. Moreover, the effective tube area is also calculated using the formula:

$$
A_{b}=\pi \times D_{0} \times\left(L_{t}-\left(N_{f} \times t_{f}\right)\right) \times N_{t}
$$

By using $L_{t}$ is length of tube and $t_{f}$ is thickness of fin. Then by using the air inlet and outlet temperature data, the average air temperature is obtained with the formula:

$$
T_{\infty}=\frac{T_{\text {inlet }}+T_{\text {outlet }}}{2}
$$

Therefore, frontal area $\left(A_{f r}\right)$ can be calculated using the formula:

$$
A_{f r}=H_{f} \times L_{t}
$$

In addition, the Air Free Flow Area $\left(A_{f f}\right)$ will be calculated using the formula:

$$
A_{f f}=\left(N_{f}-1\right) \times\left(P_{f}-t_{f}\right) \times\left(T_{f}-\left(D_{0} \times N_{t 1}\right)\right)
$$

Where $P_{f}$ is fin pitch, $T_{f}$ is Average temperature of fin, and $N_{t 1}$ is number of tubes in first row. So that the total area is obtained as:

$$
A_{t}=A_{b}+A_{f}
$$

Furthermore, the mass flow will be calculated with the formula:

$$
\dot{m}=\rho \times v \times A_{f r}
$$

By using $\rho$ is density of air, $\mathrm{v}$ is air velocity. Moreover, the hydraulic diameter is obtained using the formula:

$$
D_{h}=\frac{4 \times L_{f} \times A_{f f}}{A_{t}}
$$

Also, the minimum free flow area can be calculated using the formula:

$$
\sigma=\frac{A_{f f}}{A_{f r}}
$$

So, the maximum mass flow is obtained using the formula:

$$
G=\frac{\dot{m}}{\sigma \times A_{f r}}
$$

Then the Reynolds Number is given by:

$$
R_{e}=\frac{G \times D_{h}}{\mu}
$$

Where $\mu$ is kinematic viscousity. So, the J-Colburn Factor, $j_{W G}$, formula can be calculated with the formula:

$$
j_{W G}=0.14 R_{e}^{-0.328}\left(\frac{S_{T}}{S_{L}}\right)^{-0.502}\left(\frac{P_{f}}{D_{0}}\right)^{-0.0312}
$$

By using $S_{T}$ is transversal pitch and $S_{L}$ is Longitudinal pitch. Furthermore, the convection coefficient of the air, $h$, is given by:

$$
h=\frac{j_{W G}}{P_{r}^{\frac{2}{3}}} \times G \times C_{p}
$$

Where $P_{r}$ is Prandtl number and $C_{p}$ is heat transfer coefficient of air. After the convection coefficient has been obtained, the heat transfer rate of the fin, $q_{f}$, can be calculated using the equation:

$$
q_{f}=h \times A_{f} \times\left(T_{f}-T_{\infty}\right)
$$

The maximum heat transfer rate, $q_{\max }$, that can be transferred will be calculated using the formula

$$
q_{\max }=h \times A_{f} \times\left(T_{b}-T_{\infty}\right)
$$

By using $T_{b}$ as base temperature. So that the efficiency of the fin equation, $\mu_{f}$, will be obtained:

$$
\mu_{f}=\frac{q_{f}}{q_{\max }}=\frac{h \times A_{f} \times\left(T_{f}-T_{\infty}\right)}{h \times A_{f} \times\left(T_{b}-T_{\infty}\right)}
$$


Furthermore, to find the amount of heat transfer rate without using the fins, $q_{w f}$, using the following equation:

$$
q_{w f}=h \times A_{b} \times\left(T_{b}-T_{\infty}\right)
$$

So that the formula for the effectiveness of the fin, $\varepsilon_{f}$, is obtained using the formula:

$$
\varepsilon_{f}=\frac{q_{f}}{q_{w f}}=\frac{h \times A_{f} \times\left(T_{f}-T_{\infty}\right)}{h \times A_{b} \times\left(T_{b}-T_{\infty}\right)}
$$

\section{Results and Discussion}

Numerical simulation has been conducted for the given geometries. Fin materials such as copper, aluminum, and steel were varied for two different velocities, $8 \mathrm{~m} / \mathrm{s}$, and $15 \mathrm{~m} / \mathrm{s}$. The result is presented in the form of fin temperature contour, air temperature contour, efficiency, and effectiveness plots for every material in each different velocity.

\subsection{Fin Contour Temperature}

The fin temperature contours for three different materials at velocity $8 \mathrm{~m} / \mathrm{s}$ are shown in Figure 4. Heat source from tube wall will be distributed along the fin. For copper materials with high thermal conductivity, heat will be more evenly distributed on the fin. The fin temperature contour is dominated by red color. This indicates that the temperature of the fin around 314-315 K almost the same as the tube wall temperature. However, for steel material with low thermal conductivity, the heat source from the tube wall only diffused on the fin around the tube. As a result, the materials with high thermal conductivity have more uniform thermal distribution and better performance.

\subsection{Air Temperature Contour Between Two Tubes}

Figure 5 illustrates the air temperature contour between aluminum fin for inlet velocity $8 \mathrm{~m} / \mathrm{s}$ and $15 \mathrm{~m} / \mathrm{s}$, respectively. At $8 \mathrm{~m} / \mathrm{s}$ inlet velocity, air flows around the first tube, the velocity increases, and then the air velocity will be higher again as it goes around the second tube. The minimum transversal area $\left(S_{T}\right)$ causing free stream velocity will speed up and make wake formation become narrower at the rear part of the cylinder. Moreover, for increasing inlet velocity to $15 \mathrm{~m} / \mathrm{s}$, the boundary layer separation point will be delayed to the back position of the tube. This can cause the wake area behind the tube to become narrower. This flow pattern occurs at every row of the tube.

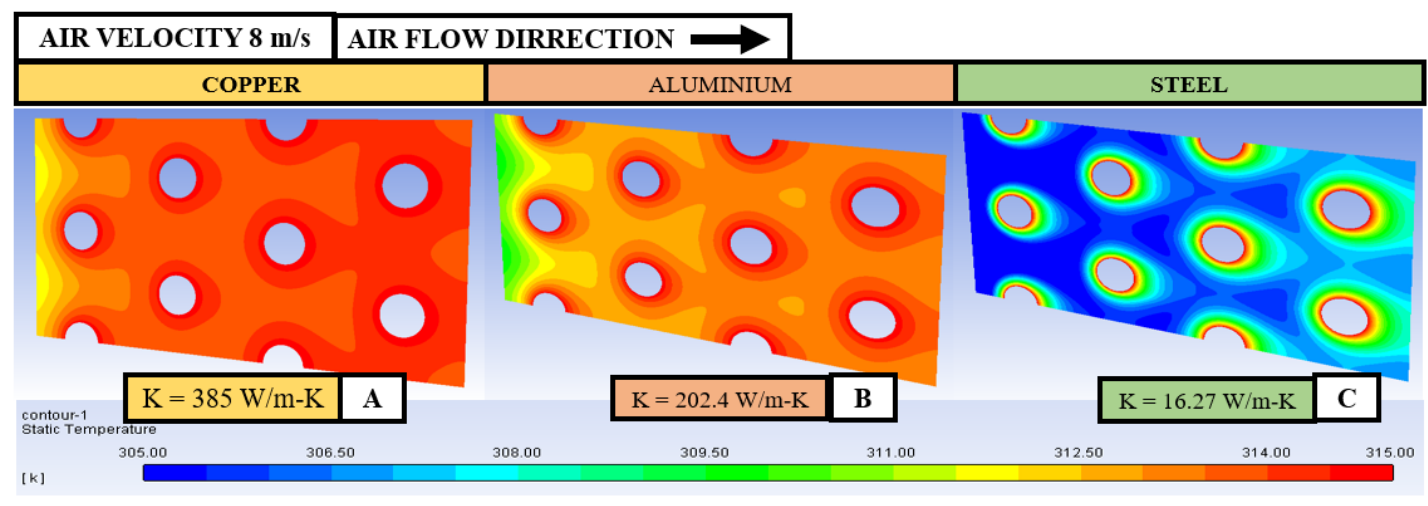

Figure 4. Fin temperature contour for different material at $8 \mathrm{~m} / \mathrm{s}$

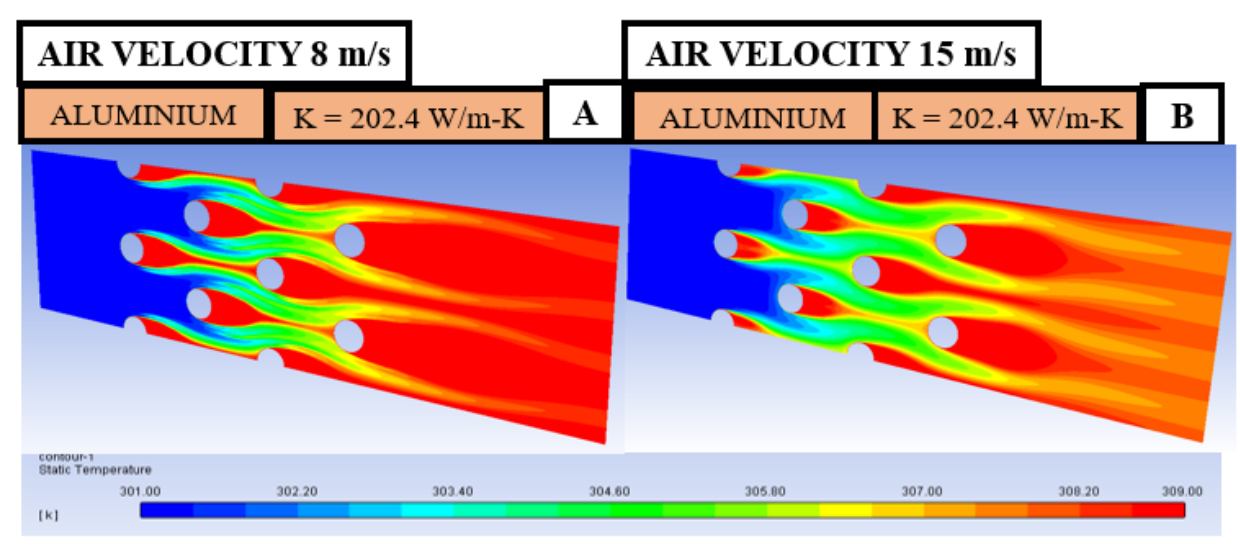

Figure 5. Air temperature contour at different velocity for aluminum fin 


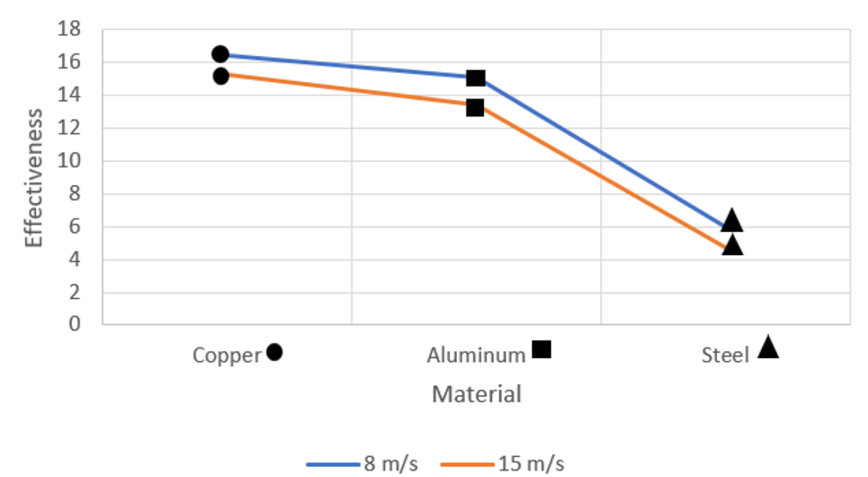

Figure 6. Fin effectiveness

\subsection{Efficiency and Effectiveness of the Fin}

The effectiveness and efficiency of the fin for each different material and inlet velocity has been calculated and is plotted in Figure 6 and Figure 7. For velocity $8 \mathrm{~m} / \mathrm{s}$, effectiveness and efficiency value are higher than velocity $15 \mathrm{~m} / \mathrm{s}$, and also, both results indicate the same tendency. At velocity $8 \mathrm{~m} / \mathrm{s}$, copper has the highest effectiveness and efficiency with 16.48 and $88.35 \%$, respectively. The gradient decreasing of effectiveness from copper to aluminum is slightly different (from 16.48 to 15.14). However, from aluminum to steel has steep decreases (from 15.14 to 5.96). This means the usage of copper and aluminum for fin materials cause relatively have the same performance in the heat exchanger. Moreover, if using steel as fin materials, there will significantly reduce the performance of the heat exchanger.

\section{Conclusions}

The three-dimensional computational studies for flow and heat transfer characteristics around flat fin and tube heat exchanger are presented. For copper material, the fin temperature contour around $314-315 \mathrm{~K}$, almost the same as the tube wall temperature. Moreover, for steel material with low thermal conductivity, heat source from tube wall only diffused on the fin around the tube. At velocity $8 \mathrm{~m} / \mathrm{s}$, copper has the highest effectiveness and efficiency with 16.48 and $88.35 \%$, respectively. Furthermore, the usage of copper and aluminum for fin materials will cause relatively have the same performance in the heat exchanger. Moreover, if using steel as fin materials, there will significantly reduce the performance of heat exchanger.

\section{References}

[1] L. Chavan and N. Purane, "Thermal analysis of pin fin using different materials and forms," International Journal of Science and Research (IJSR), vol. 4, pp. 2024-2027, Dec. 2015.

[2] Y. Kim and Y. Kim, "Heat transfer characteristics of flat plate finned-tube heat exchangers with large fin pitch," International Journal of Refrigeration, vol. 28, pp. 851-858, Apr. 2005.

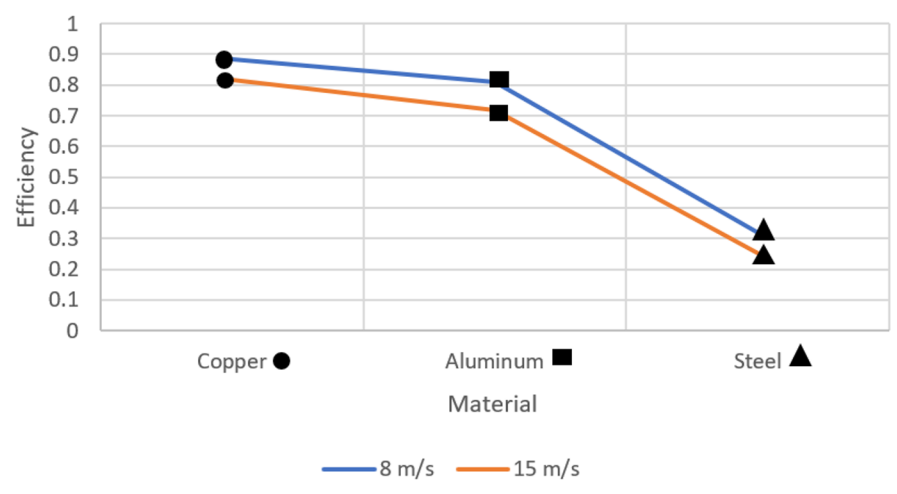

Figure 7. Fin efficiency

[3] D. Rich, "The effect of fin spacing on the heat transfer and friction performance of multi-row smooth plate fin-and-tube heat exchangers," ASHRAE Trans, vol. 79, no. 2, pp. 135-145, 1973.

[4] D. Rich, "The effect of the number of tubes rows on heat transfer performance of smooth plate fin-andtube heat exchanger," ASHRAE Trans, vol. 81, no. 1, pp. 307-317, 1975.

[5] C. Wang and K. Chi, "Heat transfer and friction characteristics of plain fin-and-tube heat exchanger, part i: New experimental data," International Journal of Heat and Mass Transfer, vol. 43, pp. 2681-2691, Oct. 1999.

[6] J. Y. Jang, M. C. Wu, and W. J. Chang, "Numerical and experimental studies of threedimensional plate-fin and tube heat exchangers," International Journal of Heat and Mass Transfer, vol. 39, no. 14, pp. 3057-3066, 1996.

[7] W. Yan and P. Sheen, "Heat transfer and friction characteristics of fin-and-tube heat exchangers," International Journal of Heat and Mass Transfer, vol. 43, pp. 1651-1659, Feb. 1999.

[8] G. A. Whan and R. R. Rothfus, "Characteristics of transition flow between parallel plates," A.I.Ch.E. Journal, vol. 5, pp. 204-208, June 1959.

[9] A. O. Elsayed and A. S. Hariri, "Effect of condenser air flow on the performance of split air conditioner," in World Renewable Energy Congress-Sweden; 8-13 May; 2011; Linköping; Sweden, no. 057, pp. 21342141, Linköping University Electronic Press, 2011.

[10] N. Jamshidi, M. Farhadi, D. D. Ganji, and K. Sedighi, "Experimental analysis of heat transfer enhancement in shell and helical tube heat exchangers," Applied Thermal Engineering, vol. 51, no. 1-2, pp. 644-652, 2013.

[11] M. Awais and A. A. Bhuiyan, "Heat and mass transfer for compact heat exchanger (chxs) design: A state- 
of-the-art review," International Journal of Heat and Mass Transfer, vol. 127, pp. 359-380, Aug. 2018.

[12] H. Basri, J. D. Nasution, A. Syahrom, M. A. Sulong, A. P. M. Saad, A. T. Prakoso, and F. Aminin, "The effect of flow rate characteristic on biodegradation of bone scaffold," Malaysian Journal of Fundamental and Applied Sciences, vol. 13, pp. 546-552, 2017.

[13] B. O. Bolaji, M. Akintunde, and T. Falade, "Theoretical investigation of the performance of some environment-friendly refrigerants in a sub-cooling heat exchanger refrigeration system," Journal of Science and Technology (Ghana), vol. 30, no. 3, 2010.

[14] S. D. Pandey and V. K. Nema, "Experimental analysis of heat transfer and friction factor of nanofluid as a coolant in a corrugated plate heat exchanger," International Journal of Experimental Thermal and Fluid Science Elsevier, vol. 38, pp. 248-256, Jan. 2012.

[15] M. V. Ghori and R. K. Kirar, "Numerical analysis of tube-fin heat exchanger using fluent," International Journal on Theoretical and Applied Research in Mechanical Engineering, vol. 1, pp. 37-44, Dec. 2012.

[16] C. Nurdiansyah, P. Prabowo, and M. Y. Abdullah, "Experimental study of r141b flow boiling compact evaporator in organic rankine cycle for waste heat recovery," IPTEK Journal of Proceedings Series, no. 1, pp. 88-91, 2019.

[17] F. P. Incropera, D. P. Dewitt, T. L. Bergman, and A. S. Lavine, Fundamentals of Heat and Mass Transfer Sixth Edition. Jefferson City: John Wiley \& Sons, 2011. 